tion of the descending colon with the sigmoil flexure. On two occasions $I$ have been able to introduce my band into the rectum, and, having detected a stricture, have acted upon information thus gained, and bave performed colotomy, the patients being females, but I have not yet succeeded in the male.

Thus, the history of the case, and the positive information obtained by exploration of the lower bowel, made the diagnosis as complete as can be expected, and I had no hesitation in proposing colotomy. In this step my colleague, Dr. Bathurst Woodman, concurred.

operation.-It is material which loin be selected, and that should be chosen which is nearest above the obstacle. The chief reasons for doing this are that the greater length of bowel may be reserved for nutrient purposes, and may also have the opportunity of quickly emptying itself; otberwise fæces in the intestine between the artificial anus and the stricture, which may be there at the time of operation or may get there afterwards, become, in proportion to their quantity, a source of discomfort to the patient. Thus, the left loin is usually selected. It will, however, occasionally happen, as in the present instance, that it is sifer to chnose the right loin, in order to be sure that the proposed opening in the colon be above the obstruction.

There are three methods of operation : that of Callisen, by longitudinal incision; that of Bauden, by oblique in cision; that of Amussat, by transverse incision. This latter I prefer, because it enables the surgeon to search forwards and backwards for the bowel, should be not reach it at once. It ronsists in making a transverse incision from three to four inches in lengtb, just a fin ser's breadth above the crest of the ilinm, the centre of which should correspond to a spot the length of the ungual phalanx of the thumb external to the outer border of the erector-spinæ muscle. At this point the loin will be opened at the outer and obliqne border of the quadratus lumborum muscle, and in a thin surject I can often detect this spot by drawing my finger from before backwards across the loin with moderate pressure. When accessible, I mark this spot with ink or iodine, and make it the centre of $m y$ incision. The integuments, fascia, and broad muscles are to be divided layer by layer-on a director, if you please, but I do not use one,-including the lumbar fascia (the origin of the transversalis muscle), and lastly the transversalis fascia, here very thin. Any vessel bleeding should be ligatured, and generally not a tablespoonful of blood is lost. The fats of the region, lobulated, will probably crop up now, either with or without pressure by the hand of an assistant upon the abdomen, and the knife may be laid aside and replaced by $t w$, pairs of forceps, with which the operator, eirher unravelling or removing, if abundant, some of this fat, will expose the intestine, and will recognise it by its greenish hue, possibly by observing a longitudinal band upon it, or by its thickness on picking it up with the fioger and thumb. This portion of the bowel, now exposed and uncovered by periton $+u m$, is to be drawn gentily out at the wound. A strong curved needle, armed with a stout silk thread, is to be passed diagonally first through one edge of the wound, then across the portion of bowel that is to be opened, and lastly through the other edge of the wound. Then a second is to be passed at a right angle to the former. The buwel is now to be opened to the extent of an inch by a longitudinal incision. The threads, previously in troduced on the veedles, will now be found in the interior of the bowel, and should be gently drawn from within it either by the finger or a blunt hook and divided. They will now be equivalent to four sutures, to be at once made to maintain the wound in the bowel patent.

In cutting into the loin $I$ practise section of the soft parts to the least necessary degree, with a view to weaken the abdominal wall as little as possible, so as to prevent undue prolapse. Thus the incision in the skin is much longer tban the wound in the lumbar fascia. ${ }^{1}$ Also I bring the edges of the anterior half of the wound together with one or two sutures, but allow the posterior portion to gape, and thus to form a channel along which the fæces may flow readily, and not infil trate the loin.

Caution.-The operator must not mistake the lobulated fat of the loin (an error very easily made) for the colon; nor the kidney for hardened fæces within the bowel.

I See Operative Surgery, second edition, p. 286, by C. F. Maunder.
Should the origin of the quadratus lamborum muscle be unusually wide, the edge of its sheath may be nicked, but not otherwise.

After treatment - Very little beyond cleanliness is refuluisite. Sometimes a small warm-water enema is useful to relieve constipation, and hardened fæces on the distal side of the wound may occasionally be removed by a scoop. Should the neighbourhood of the artificial anus become excoriated, it may be painted with castor oil, suggested to me by Mr. Gordon Brown for a similar purpose. A soft pad and a bandage are the only retentive apparatus usually necessary; and Dr. Miguire, of Stony Stratford, writing to me ten weeks subsequent to operation, concerning one of my cases seen by me in consultation with him and Dr. Francis, of Nor hampton, says:- "The artificial anus is a perfect success in every way; it never attracts our attention, and we seldom bestow a thought on it."

The patient whose case is under consideration expressed himself as being much relieved by the operation and "very" jolly." Vomiting ceased immediately, and the bowels emptied themselves through the wound. Hiccough, however, persisted, and he died about a week subsequent to operation.

You must understand that the morbid conditions for the relief of which colotomy is performed are various. I have operated tbirteen times-eleven in the lef $t$ and twice in the right loin-for complete obstruction; for incomplete obstruction threatening death by vomiting; for obstinate stricture, both malignant and benign, associated in two instances with a vesico-intestinal fistula; and for painful and bleeding bnt non-obstructive cancer of the rectum. In the great majority the relief afforded was immediate, and was testified by the patients in the must forcible and unmistak able language. In more than one instance I regretted very much that the operation had not been performed sooner, although it forded an easy death. This in itself is a suf ficient justification for an operation which can be done with comparative facility and rapidity, as easily and as quickly as the majority of operations for strangulated hernia (this patient was not halt an hour in the theatre). The subjects being generally thin, the necessary wound is neitber long. nor deep, and prolonged suppuration need not be anticipated. In one of my patients, aged sixty, the wound about the artificial anus was healed on the third day, and her medical attendant, Mr. Pearce, informed we that on the fifth day this lady sat up and partook of roast mutton. vegetables, and beer. There is little or no bleeding, not single ligature being requisite sometimes.

\section{ON RINGWORM OF THE HEAD, AND ITS MANAGEMENT.'}

By TILBURY FOX, M.D., F.R C P.,

PHYSICIAN TO THE DEPARTMENT FOR SKIN DISEARES IM UNIVRESTY COLLEGE HOSPITAL.

\section{INTRODUCTORY OBSERVATIONS.}

IT is beyond question that the results of the treatment of ringworm of the bead are, in the majority of cases, eminently unsatisfactory and disappointing. There are, no doubt, certain special difficulties which stand in the way of a rapid cure of the disease in most instances. But, making due allowance for this fact, the truth of the assertion $I$ have made must be admitted, considering especially that the disease is of the commonest occurrence, and therefore affords ahundant opportunity for study; that its proximate cause is well understood; that the essential diseased condition is readily accessible to remedies; and, lastly, that both medical men and those who have charge of ringworm patients are always anxious to get rid of such a potent source of evil, if only on account of the serious consequences of the necessary isolation of the infected demanded by the contaginusness of the disease.

The faults of the existing defective management of ringworm lie in part at the door of the practitioner, and in part

1 Read in abstract before the West Kent Medico-Chirurgical Society. 
at that of persons immediately in charge of ringworm cases, and who fail to carry out effectually the directions of the practitioner. I propose to point out, as briefly as I can, what these faults are, and then to offer some practical observations relative to the diagnosis and treatment of the disease under notice.

In the first place, as a result of the common occurrence of failure in satisfactorily treating ringworm cases, there does unquestionably exist on the part of most practitioners a feeling of dislike to have any dealings with them. The existence of such a feeling is incompatible with that careful examination and thoroughness and determinedness in the choice and use of remedies without which treatment is a failure. This state of things is much to be regretted, because in my own opinion the exercise of a little more trouble and patience would remove the obstacles which commonly stand in the way of a successful dealing with ringworm of the head in the majority of cases, and would reduce the number of obstinate and rebellious instances of the complaint to an inconsiderable minority. The practitioner must generally expect to have his patience tried by the difficulty of getting his directions fully and fairly carried out, and against this he must make due provision.

In the second place, the treatment adopted is based upon an imperfect conception of the mischief to be remedied. Bingworm is a disease due to the growth of a vegetable fungus which insinuates itself about and amongst the shaft and fibres of the hair and epithelial tissues. It is obstinate when the scalp is the seat of disease, from the fact that the parasite effects a lodgment in the deepest part of the hair follicle, and is out of the ready reach of remedies capable of destroying it. The treatment usually employed does not seem to be based upon a sufficient appreciation of this fact. Too much attention is paid to the mere surface changes in ringworm, and decidedly too little stress is laid upon the fact that the difficulty of curing the disease depends essentially upon the existence of the fungus and its active growth at the lowest part of the hair follicle, where it lies ensconced out of the easy reach of parasiticides; its growth being, however, favoured more or less by certain general nutritive conditions. I do not mean to say that practitioners affirm the superficiality of the disease in so many words, but I do mean to aver that the treatment adopted suggests that they are unconsciously or seemingly actuated by such a belief. The real object to be zept in view is the removal of the diseased hairs and the fungus in and about them; but attention is too much directed to the state of the scalp itself. For mere eruption, and its degree and results, are of little moment in a therapeutic point of view, except in so far as they are caused by the application of irritants, in which case they are a guide to the extent to and frequency with which the latter may be conveniently repeated.

From the moment a case of ringworm comes under observation until the time that it can with certainty be pronounced well, the condition of the hairs is the chief thing to be watched. The only a fe guide to prognosis and to a proper estimate of the progress of the disease towards cure is to be obtained by attention to the state of the hairs of the diseased part. I lay so much stress upon this point because \$o many fail to recognise its importance, especially in regard to prognosis. I can truthfully say scarcely a week passes but I see cases of ringworm pronounced well because there is no apparent scaliness, and the hair appears to be growing fairly well again on the site of the diseased areas, when all the while there are characteristically diseased hairs intermingled with, but perhaps concealed by, healthy ones, or stadding over the supposed recovered spot. The recognition of these morbidly altered hairs is not an easy matter in some instances, particularly in light-haired children. It is often necessary to search carefully for them with a good lens and plenty of light, precautions frequently neglected, but only to involve a serious mistake in prognosis or diagnosis. Of course those who do not possess good eyesight, or who discard the lens, wholly overlook the condition.

In the third place, in diagnosing ringworm, it is needful to guard against the error, which is often committed, of considering that there is a general uniformity in its nakedeye features; that, for instance, the diseased surface is always circular in form and scurfy, \&c. As I shall point out further on, the disease is not always composed of "rings," but varies greatly in its clinical aspects. Although the circular character of patches may be entirely absent, zet, however, the diseased hairs are always present.

In the fourth place, in dealing with the treatment of the disease in detail, it is of prime consequence to recounise and act upon the fact that the disease, as I have already hinted, varies vastly in the degree of its hold upon the surface, according to the state of health of the attacked subject. General treatment may not be needed in some cases, but it is essential to the cure of the disease in others, and must be formulated in accord with several important considerations. The want of attention to this point greatly encourages blind faith in specifics. No differences are seen in the characters of different cases, and consequently all are treated alike. This topic will be duly noticed.

In the fifth place, the directions given to those who are entrusted with the care of ringworm cases are often not sufficiently explicit and urgent. If the medical practitioner is himself not duly impressed with the necessity of unusual precautions and perseverance in the vigorous treatment of the disease, it is not to be expected that the attendant will appreciate the fact. What is needed is that the mother or nurse in charge of the affected child should be impressed by the practitioner with the conviction that the real difficulty in curing the disease is getting the remedies by due friction to be brought fully into action upon the fungus at the deepest part of the follicle or the root of the hair, and that this difficulty can only be overcome by constant, continuous, and free application, or infriction of remedies, after all hair crusts and other ohstacles about the scalp have been carefully removed. Unless this is effected, attendants are satisfied with a mere superficial application of medications. It is not an easy matter to instil this conviction into the minds of attendants, and if in the management of ringworm some blame attaches to the doctor for a due want of appreciation of the point under notice, much more lies at the door of parents and others who are called upon to use the measures prescribed for the cure. Children with ringworm are not ill, and so many parents cannot understand the necessity for the constant supervision of cases by the medical men, and use their own judgment in the matter, even when pains are taken to explain to them the natural difficulties which delay the cure of ringworm. Then the love of quackery and specifics is so very strong amongst the public that, un. less the progress is what they themselves decide is proper, they are apt to chop and change about from remedy to remedy upon the recommendation of almost anyone, provided he or she be not medical. It is further assumed that ringworm must be the same in all cases, and what will cure one case should be equally efficacious in another, whereas variations in the state of the general health greatly modify the intensity of the disease in different instances. There are other minor difficulties against which the medical man has to contend, and chief amongst these must be mentioned the desire of parents to retain the hair of children, and their opposition to its removal when really necessary for the ascertainment of the actual amount of disease present, and the prevention of its spread to new points. A great number of cases lapse into a chronic state on account of a want of care in these points. On account of the frequent obstinacy of the disease, the very serious inconvenience and loss of educational advantages contingent upon the banishment of the infected from schools, the pecuniary loss to those who are concerned in education by the breaking out of the pest of ringworm in school, and the consequent paramount importance of checking the disease as speedily as possible, in view of the probable dissemination among the healthy in families, schools, and institutions where the young are congregated, it is imperative that close attention should be given to the lesser as well as the greater matters of therapeutic detail. In regard to no other disease can it be said that it is more needful that the treatment should be conducted with great definiteness and decision, and to that end the preceding general observations, no less than those which follow, I hope may tend.

\section{GENERAL DESCRIPTION OF RINGWORM.}

The term " ringworm" is used by most modern writers as a generic designation for the group of diseases caused by the attack upon the skin of vegetable parasites; but popularly it means the common ringworm of schools, which 
attacks the scalp and the body, and in that sense I employ it in the succeeding remarks. This common ringworm of the head, or tinea tonsurans, and of the body, tinea circinata, is caused by the attack of the trichophyton tonsurans. The disease is essentially contagious, the contagious element being the fungus.

Ringworm of the Head attacks children, except in rare instances. It is said not to occur in the adult, but this is a mistake. I have seen even severe cases in adults of from twenty-one to forty years of age.

Ringworm of the Body, which occurs in the form of red scurfy rings, is observed in persons of all ages, but it is more common in the young. The difference in aspect, as compared from ring worm of the scalp, is due to the absence of hair in the one locality and its presence in the other. In hot climates-India, China, South America, \&c.-under the influence of heat and moisture the fungus grows very luxuriantly, and the disease is much more severe and extensive, covering large portions or whole regions of the body, in the form of large, well-defined, bright-red, scurfy, itchy, and even infiltrated patches or rings, but $I$ do not purpose to deal with this tropical phase of the disease here.

The fungus (the trichophyton tonsurans) occurs in varying luxuriance. Its rate and power of persistent growth, its rapidity of reproduction, and the special aptitude which it exhibits for certain surfaces, are very different in different instances. Sometimes its growth is very feeble, and it is easily destroyed, and vice versd. The differences in these respects are to be accounted for, not only by the more favourable nidus which it meets in some as compared with other persons, but also by the favourable concurrence of external conditions, such as the presence of heat and moisture, as in tropical parts ; and likewise anatomical considerations, since in the more hairy parts the fungus, with its predilection for the hair structure as its seat of growth, penetrates more deeply in such localities to the bottom of the follicle, and there nestles out of the reach of agencies that destroy it. In non-hairy parts it is more liable to be killed.

When the fungus effects a lodgment upon the surface it acts in several ways: firstly as an irritant, cansing a certain amount of inflammation with attendant redness and effusion, and subsequently desquamation; secondly, it appropriates the moisture, and probably the nutrient material of the hair in hairy parts, and so alters the hairs texturally, rendering them dry, lustreless, and brittle, and subsequently in chronic cases fatty, whilst the mere force of its growth and increase in bulk splits up the hair shaft, and otherwise disorganises its tissues, which it invades; and, thirdly, it destroys and prevents the formation of the root sheaths, and leads to the blockage of the follicles by débris. In non-hairy parts it invades and inflames the epithelial tissues more especially, and the circularity of the tinea patch is due to the fact that the fungus grows and irritates equally in all directions from a common centre.

Practical application.-From this brief general outline of the nature of ringworm it will be evident that there are three main elements of which ringworm is composed.

1. The state of health or nutrition which supplies the nidus for the growth of the fungus, or, in other words, the soIL.

2. The fungus or PARAsite itself.

3. The effects produced upon the tissues by the growth of the parasite.

It is important to bear in mind the composite character of ringworm, because it has a direct bearing upon the successful treatment of the disease. Ringworm is obstinate in proportion as this or that patient offers a favourable soil in his textures for the growth of the fungus or parasite. The skin absorbs sluggishly and scantily even with considerable friction, especially at a diseased site, in ringworm, and in all cases where the mischief has fully established itself in the skin the difficulty of getting parasiticides into contact with the fungus or parasitic elements at the deeper parts of the bair.follicle-and it must be recollected that this reaches to a point below the true skin-is not slight. If the fungus grows languidly - which implies only a slightly favourable soil-it will be the more readily destroyed; but if it grows luxuriantly-it will do this in proportion as the general nutritive condition furnishes a favourable nidus-it will be more difficult, because in reality the rate of growth and increase of the fungus may exceed the degree of de- structiveness of the infricted remedy, unless special provision is made that this shall not be the case by general internal measurea, as well as greater vigour in the use of local means. In the case of the application of potent remedies, such as blistering fluids, it must be remembered that the parasiticidal operation of the drug does not extend in many cases so deeply as the deepest part of the follicle, and other measures of internal operation are needed to help to starve out the fungus. The curability of ringworm, therefore, is effected not only by the adoption of all that tends to increase the absorption of parasite-killers, but also such general remedies as are calculated to alter the state of nutrition which furnishes the favourable seed-ground for the ringworm growth.

(To be continued.)

\section{CASE OF RHEUMATIC FEVER SUCCESS- FULLY ARRESTED IN FIVE DAYS BY THE USE OF SALICIN.}

BY K. N. MACDONALD, M.D. ERLUNG., F.R.C.P. ED., \&c。

As the treatment of rheumatic fever by salicin is now upon its trial, the following case appears to me a fair instance of the great therapeutic value of that agent, so far as can at present be reasoned from clinical experience.

J. $\mathbb{M}-$, a printer, aged twenty-eight, of dark complexion and spare habit of body, enjoyed very fair health up to September, 1873, when he was seized with an attack of rheumatic fever following an eruption of boils in the axills, on which occasion he was confined to his bed for nine weeks with severe pain and swelling in all the large joints, accompanied by a severe pain in the region of the heart, which his then medical attendant assured him implicated that organ.

He made a good recovery, however, and, with the exception of some weakness, he resumed his occupation as before without experiencing any uneasiness until the 10th February, 1877, when, on exposure to damp after a hard day's work, he was seized with rigors, pains in the joints, and a swelling in the left axillary space, similar to, though not perhaps so. severe at the commencement, as the attack he had in 1873.

His symptoms increased on the 11 th, and I was called in on the 12th, when I found him in the following condition: The large joints of the upper and lower extremities exquisitely tender and swollen, the head and neck immovably flxed, pain in the præcordial region, with a slight systolic bruit heard loudest: at the apex, high fever, suffusion of the eyes, great restlessness, sour-smelling sweat, high-coloured urine loaded with urates, and general constitutional disturbance. Temperature $102^{\circ}$, pulse 120 in the minute, furred tongue, constipation, with an insatiable thirst, which rendered him a very helpless object.

I immediately put him upon ten-grain doses of salicin every four hours, at the same time administering a saline mixture containing twenty grains of bicarbonate of potash three times a day, with ten grains of Dover's powder at bedtime, and potash, soda, or lithia water ad libitum. The affected joints were wrapped up in cotton wool covered over with oiled silk, and a mustard plaster, followed by a linseedmeal poultice, applied to the region of the heart, a cradle having been placed underneath the bed-clothes to prevent their weight being felt over the knee-joints.

Feb. 13th.-Passed a better night, slept at intervals for a very short time, but in other respects not much improred. Complains of severe headache. The neck, elbows, wrists, knees and ankle-joints exquisitely painful and immovable. Pain in the region of the heart somewhat abated, but increased on leaving off the poultice. Temperature $102^{\circ}$; pulse 115, smaller, and more compressible-in fact, feebler than at yesterday's visit. Continue treatment; spare diet, milk, arrowroot, slops, \&c. To take an ounce of castor oil, and a second dose of the Dover's powder after midnight if necessary.

14th. - Passed a restless night. The second dose of Dover's powder gave considerable relief towards morning, tho oil 